\title{
Proteomic analysis of cerebrospinal fluid for relapsing-remitting multiple sclerosis and clinically isolated syndrome
}

\author{
ZBYŠEK PAVELEK ${ }^{1}$, OLDŘICH VYŠATA ${ }^{1}$, VOJTĚCH TAMBOR ${ }^{2}$, KRISTÝNA PIMKOVÁ $^{2}$, \\ DAI LONG VU ${ }^{2}$, KAMIL KUČA ${ }^{2}$, PAVEL ŠT̃OUAČ ${ }^{3}$ and MARTIN VALIŠ ${ }^{1}$ \\ ${ }^{1}$ Department of Neurology, Faculty of Medicine and University Hospital Hradec Králové, Charles University in Prague; \\ ${ }^{2}$ Biomedical Research Center, University Hospital Hradec Králové, CZ-500 05 Hradec Králové; ${ }^{3}$ Department of Neurology, \\ Faculty of Medicine and University Hospital Brno, CZ-639 00 Brno, Czech Republic
}

Received February 12, 2016; Accepted April 25, 2016

DOI: $10.3892 /$ br.2016.668

\begin{abstract}
Early diagnosis and treatment of multiple sclerosis (MS) in the initial stages of the disease can significantly retard its progression. The aim of the present study was to identify changes in the cerebrospinal fluid proteome in patients with relapsing-remitting MS and clinically isolated MS syndrome who are at high risk of developing MS (case group) compared to healthy population (control) in order to identify potential new markers, which could ultimately aid in early diagnosis of MS. The protein concentrations of each of the 11 case and 15 control samples were determined using a bicinchoninic acid assay. Nanoscale liquid chromatography coupled with tandem mass spectrometry was used for protein identification. Proteomics data were processed using the Perseus software suite and $\mathrm{R}$. The results were filtered using the Benjamini-Hochberg procedure for the false discovery rate $(\mathrm{FDR})$ correction $(\mathrm{FDR}<0.05)$. The results showed that, 26 proteins were significantly dysregulated in case samples compared to the controls. Nine proteins were found to be significantly less abundant in case samples, while the abundance of 17 proteins was significantly increased in case samples compared to controls. Three of the proteins were previously linked to RR MS, including immunoglobulin (Ig) $\gamma-1$ chain $\mathrm{C}$ region, Ig heavy chain $\mathrm{V}$-III region $\mathrm{BRO}$ and $\mathrm{Ig} \mathrm{K}$ chain $\mathrm{C}$ region. Three proteins that were uniquely expressed in patients with RR MS were identified and these proteins may serve as prognostic biomarkers for identifying patients with a high risk of developing RR MS.
\end{abstract}

Correspondence to: Dr Zbyšek Pavelek, Department of Neurology, Faculty of Medicine and University Hospital Hradec Králové, Charles University in Prague, 581 Sokolská, CZ-500 05 Hradec Králové, Czech Republic

E-mail: zbysekpavelek@email.cz

Key words: multiple sclerosis, clinically isolated syndrome, cerebrospinal fluid, proteomic analysis, biomarkers, proteins

\section{Introduction}

Multiple sclerosis (MS) is a disease characterized by immunopathological damage to the structures of the central nervous system (CNS) and neurodegenerative changes in the brain (1). MS typically presents at a younger age, between the 20th and 40th years of life. The first neurological signs, which are suspected to increase the risk of developing clinically definite MS (CDMS), are termed clinically isolated syndrome (CIS) and consist of episodes of inflammation in one or more parts of the CNS for at least $24 \mathrm{~h} \mathrm{(2).} \mathrm{The} \mathrm{characteristics} \mathrm{of} \mathrm{CIS}$ include typical symptoms of MS outbreaks over hours or days, magnetic resonance imaging (MRI) findings compatible with the diagnosis of MS, remission periods lasting a few weeks, and radiological progression of lesions compatible with demyelination (3). The diagnosis of the disease is based on clinical examinations including MRI of the brain and spinal cord, supported by the examination of cerebrospinal fluid (CSF) (4-8).

The results of clinical studies and research confirmed that the early diagnosis and treatment of MS during the initial stages of the disease can significantly retard its progression, preserve long-term performance and prevent permanent damage to the nervous structures (9). The benefits of early long-term treatment initiation for MS are based on the data published by Miller in 2004, showing that patients started to be treated later did not experience the same benefits of treatment compared to those who started treatment in the early stages of the disease (10). As a result, there has been an intense effort in the search for new disease markers to enable early diagnosis and treatment with the aim of retarding disease progression. Previous proteomics analyses of the CSF have detected a number dysregulated proteins, which were altered in MS patients (11-13). Moreover, several published proteomic studies compared various MS subgroups to control groups and revealed candidate biomarkers for MS (14-16). These studies identified a large number of potential biomarkers, likely due to different proteomics approaches and the high heterogeneity of MS.

The aim of this study was to identify changes in the CSF proteome in patients with RR MS and CIS who are at a high risk of developing MS (case) compared to healthy population (control). 


\section{Materials and methods}

Materials. Subjects (patients and healthy controls) enrolled in the present study provided written informed consent for the collection of CSF samples.

The CSF samples were collected using a standard lumbar puncture technique with a single-use atraumatic needle (Pajunk, Geisingen, Germany). Chemicals were purchased from Sigma-Aldrich (St. Louis, MO, USA) and were of the highest grade available, unless otherwise indicated.

Sample preparation and tryptic digestion. The protein concentrations of each of the 11 cases and 15 control samples were determined using a bicinchoninic acid assay (BCA) (Sigma-Aldrich). An equal amount of $50 \mu \mathrm{g}$ of protein was taken from each sample for subsequent steps. The $\mathrm{pH}$ was adjusted using triethylammonium bicarbonate buffer (Sigma-Aldrich), pH 8.5 to a final concentration of $200 \mathrm{mM}$. Sodium deoxycholate (SDC) at a final concentration of $1 \%$ was used for protein solubilization and digestion enhancement.

The proteins were reduced using $5 \mathrm{mM}$ Tris (2-carboxyethyl) phosphine hydrochloride for $1 \mathrm{~h}$ at $60^{\circ} \mathrm{C}$ and thiol groups were blocked in $10 \mathrm{mM}$ methyl methanethiosulfonate for $30 \mathrm{~min}$ at a room temperature of $24^{\circ} \mathrm{C}$. Proteins were digested using a combined LysC/trypsin strategy. First, the samples were digested with LysC (Promega, Madison, WI, USA) at a 1:50 enzyme to protein ratio $(\mathrm{w} / \mathrm{w})$ for $4 \mathrm{~h}$ at $37^{\circ} \mathrm{C}$. Trypsin (Promega) was then added at the same ratio, followed by overnight incubation at $37^{\circ} \mathrm{C}$.

Digestion was terminated by the addition of trifluoroacetic acid (TFA) to a final concentration of $1 \%$ and SDC was removed by a liquid-liquid extraction using water-saturated ethyl acetate (5X $200 \mu 1$ ). The organic phase was discarded, and the remaining ethyl acetate traces in the aqueous phase were removed in speed-vac. The samples were desalinated using Empore C18-SD SPE cartridges (3M, St. Paul, MN, USA).

Nano liquid chromatography-tandem mass spectrometry (LC-MS/MS) analysis. The samples were redissolved in loading phase A ( $2 \% \mathrm{AcN}, 0.1 \%$ TFA) at a concentration of $0.5 \mu \mathrm{g} / \mu 1$ and subjected to a nanoLC-MS/MS analysis. An UltiMate 3000 RSLCnano system (Thermo Scientific, Bremen, Germany) was used for chromatography separation. The trapcolumn configuration consisted of a PepMap100 C18, $3 \mu \mathrm{m}$, $100 \AA ̊, 75 \mu \mathrm{m} \times 20 \mathrm{~mm}$ trap column and a PepMap RSLC C18, $2 \mu \mathrm{m}, 100 \AA ., 75 \mu \mathrm{m}$ x $500 \mathrm{~mm}$ analytical column (all from Thermo Scientific). The samples were loaded onto the trap column at $8 \mu \mathrm{l} / \mathrm{min}$ of loading phase $\mathrm{A}$ for $3 \mathrm{~min}$. Peptides were separated by a linear gradient formed by mobile phase $\mathrm{A}$ ( $2 \% \mathrm{AcN}, 0.1 \% \mathrm{FA})$ and mobile phase B ( $80 \% \mathrm{AcN}, 0.1 \% \mathrm{FA})$, running from 2 to $40 \%$ of mobile phase B in 240 min at a flow rate of $200 \mathrm{nl} / \mathrm{min}$.

Eluted peptides were electrosprayed into a Q-Exactive Plus mass spectrometer using a Nanospray Flex Ion Source (both from Thermo Scientific) at $1.8 \mathrm{kV}$. A full MS/Top10 experimental setup was used. Positive ion full scan MS spectra $(\mathrm{m} / \mathrm{z} 400-1,600)$ were obtained using a $3 \times 10^{6}$ AGC target in the Orbitrap at 70,000 resolution with a maximum ion time of $100 \mathrm{msec}$. A lock mass of $\mathrm{m} / \mathrm{z} 445.12003\left(\left[(\mathrm{C} 2 \mathrm{H} 6 \mathrm{SiO}) 6^{+} \mathrm{H}\right]^{+}\right)$ was used for internal calibration of mass spectra.
Precursor ion charge state of $\geq 2>8$ and threshold intensity of $1.7 \times 10^{4}$ counts, corresponding to $1 \%$ 'underfill ratio', were selected for HCD fragmentation, with an exclusion window of $15 \mathrm{sec}$. The isolation window of $2 \mathrm{~m} / \mathrm{z}$ and normalized collision energy of 28 were used. Each product ion spectrum was obtained in the Orbitrap at 17,500 resolution, with a $1 \times 10^{5}$ AGC target and a maximum injection time of $60 \mathrm{msec}$.

LC-MS/MS data analysis. Raw LC-MS/MS files were processed in the MaxQuant software (version 1.5.2.8) (17). MS/MS spectra were searched using the built-in search engine Andromeda against a reviewed SwissProt human protein database containing 20,204 entries downloaded from UniProt. org in March 2015 (18). Trypsin/P was set as a protease with up to two missed cleavages allowed. The maximum mass deviation tolerance in MS mode was set to $20 \mathrm{ppm}$ for the initial search and $6 \mathrm{ppm}$ for the main search, whereas the maximum deviation tolerance in MS/MS mode was set to $20 \mathrm{ppm}$. Thiomethylation of cysteine residues was set as fixed modification, while oxidation of methionine and $\mathrm{N}$-terminal protein acetylation were selected as variable modifications. The false discovery rate (FDR), determined by reverse database searching, was set to 0.01 for the peptides and proteins. Label-free quantification was performed using the MaxLFQ engine integrated in MaxQuant (19).

Bioinformatics analysis. Proteomics data were processed using the Perseus software suite (http://www.perseus-framework.org/) and R (20). First, data were transformed $[\log 2(\mathrm{x})]$ and filtered so that for each protein, at least one group (case/control) contained a minimum of 50\% valid values. The remaining missing values were imputed by random numbers drawn from a normal distribution in Perseus (19). The data were then normalized in R using locally weighted scatterplot smoothing (LOWESS) algorithm (21). Subsequent steps were then performed in Perseus. A two-tailed, two-sample t-test and was used to compare protein levels between the case and control groups (22). The results were filtered using the Benjamini-Hochberg procedure for FDR correction (FDR $<0.05)$. Statistical significance for t-test was then standardized at an $\alpha$ level of $\mathrm{P}<0.002$.

\section{Results}

LFQ intensities. An MS-based quantitative proteomics strategy was used in the present study to perform a proteome-wide comparison between 15 samples from the healthy population (control group) and 11 samples from RR MS and CIS patients (case group). The 26 samples were analysed using label-free high-resolution shotgun proteomics in technical duplicates. The 52 result files obtained were subsequently processed using the MaxQuant software and the Andromeda search engine. The 'match between runs' algorithm in MaxQuant was applied, which enabled peptide identifications to be matched and transferred between runs at an FDR $<1 \%$. This initial dataset contained 9,089 peptides corresponding to 965 protein groups.

Protein quantification was performed using the MaxQuant label-free algorithm (LFQ) with unique and razor peptides for protein quantification, and $\geq 2$ ratio counts were required for a protein quantification to be considered valid. Technical 


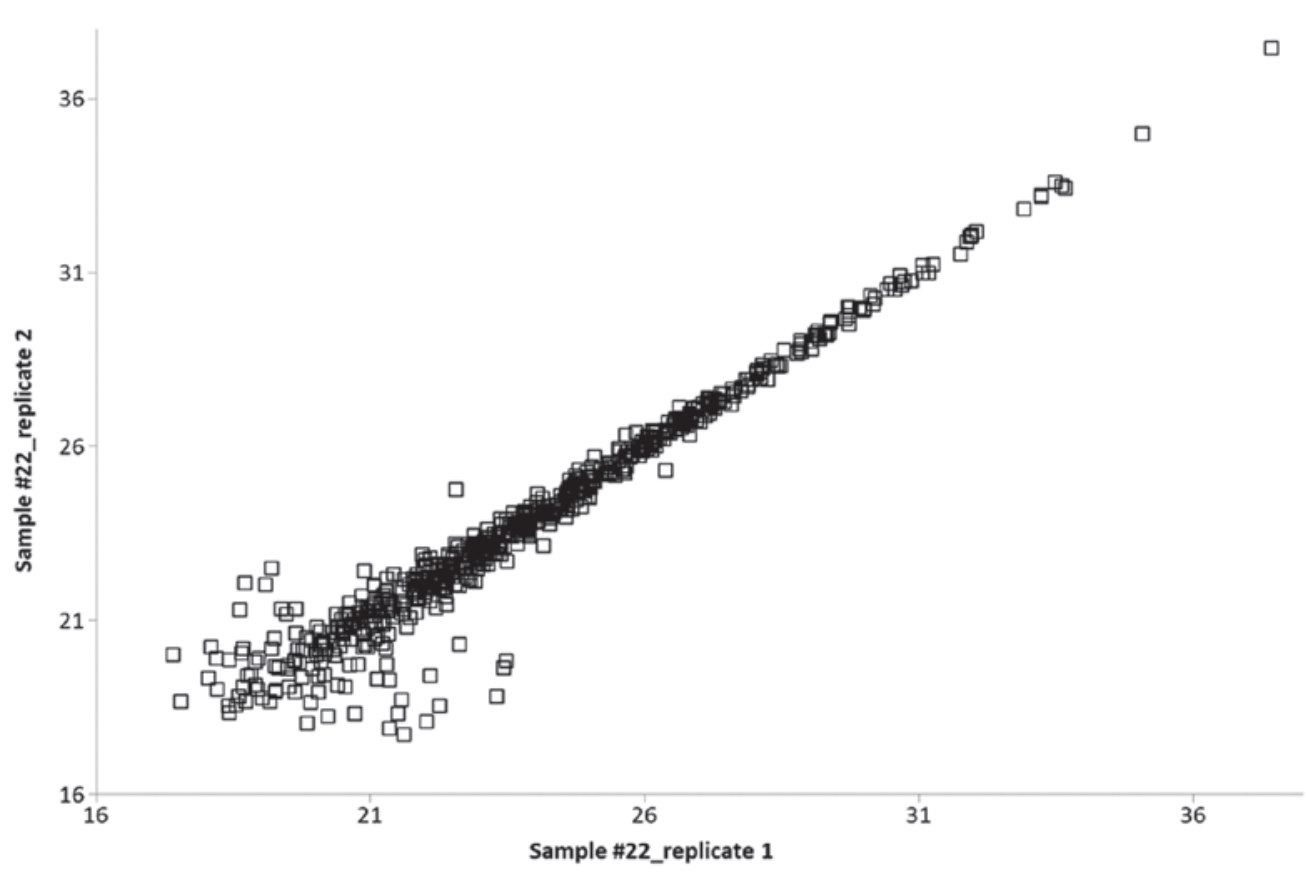

Figure 1. Pearson's correlation of protein LFQ intensities between the two technical replicates of one representative sample, R=0.976.

replicates were compared with each other, and the Pearson correlation was calculated. High values of R (0.90-0.98) represented a highly reproducible, relative label-free quantification between technical replicates (Fig. 1).

Label-free quantitative approaches are often accompanied by an absence of data on particular proteins/peptides. This feature of missing values can occur due to a low abundance of proteins/peptides as well as to post-translational modifications or even because of technical reasons (23). The filtering of missing values in the initial dataset of 922 protein groups with the subsequent imputation of remaining absent values was performed with respect to the above reasons to avoid the incorrect rejection of potential marker candidates. The initial data were filtered in order that a valid LFQ value for a given protein was present in $\geq 50 \%$ of samples in at least one cohort (case/control). Using this strategy, even if a protein was present in one cohort and absent in the other, it would not be rejected due to missing LFQ information. The remaining missing values were subsequently imputed as described above. The final dataset for bioinformatics evaluation contained 627 identified protein groups in each sample.

Dysregulation of 26 protein groups. To determine significant differences in protein abundance between the case and control samples, the LFQ intensities of each protein group were compared using the t-test corrected with the Benjamini-Hochberg FDR $(\mathrm{P}<0.05)$ method. We found 26 protein groups to be significantly $(\mathrm{P}<0.002)$ dysregulated in the case samples compared to the controls (Table I).

Volcano plot and boxplot graph. To graphically represent the t-test data, a volcano plot was created (Fig. 2). Points above the non-axial horizontal line are proteins with significantly different abundances in the case and control samples. The differences in case vs controls for each of the dysregulated proteins is shown in Fig. 3. Nine proteins were found to be significantly less abundant in the case samples, while the abundance of 17 proteins was significantly increased in the case samples compared to the controls. Differentially abundant proteins were classified according to the Gene Ontology Biological Process categories. Less abundant proteins were preferentially involved in biological adhesion, cell killing, transmembrane transport, anatomical structure development and morphogenesis, whereas the more abundant proteins were associated with the immune system, metabolic processes and homeostatic processes.

\section{Discussion}

A number of studies have examined risk factors in patients with CIS in relation to the development of CDMS (24-30). The RR form of MS develops in approximately $60-80 \%$ of patients. The factors predicting a lower risk of early conversion to CDMS include monofocal CIS, disability afferents (isolated syndrome sensitive), and normal or non-specific findings on MRI. Similarly, the factors predicting a higher risk of early conversion to CDMS can include multifocal CIS, disability efferent pathways, and abnormal findings on MRI with multifocal lesions (25). One crucial factor in determining the risk of conversion to CDMS CIS is the primary finding by MRI, with the initial lesion load, i.e., the number and volume of T2-weighted lesions, showing prognostic importance $(26,27)$. Atrophy of the brain was also found to play an important role, as patients who developed a second attack showed greater total brain atrophy and atrophy of grey matter than patients in whom the second attack did not occur (28). Another risk factor in the development of CDMS is considered to be the presence of oligoclonal bands (OCBs) (29-31). Thus, each of the above factors may predict the progression of CIS to CDMS.

Three of the 26 dysregulated proteins identified in the present study were also identified in the reports of Kroksveen et al in patients with RR MS, including immunoglobulin (Ig) $\gamma-1$ 
Table I. A list of 26 protein groups significantly $(\mathrm{P}<0.002)$ dysregulated in the case samples compared to the controls a

\begin{tabular}{|c|c|c|c|c|}
\hline $\begin{array}{l}\text { Uniprot } \\
\text { accession no. }\end{array}$ & Protein names & $\begin{array}{l}\text { LFQ median value, } \\
\text { case group }\end{array}$ & $\begin{array}{l}\text { LFQ median value, } \\
\text { control group }\end{array}$ & $\begin{array}{l}\text { Case vs. control, } \\
\text { LFQ ratio }\end{array}$ \\
\hline Q9NZK5 & Adenosine deaminase CECR1 & 1957797.34 & 935384.50 & 2.09 \\
\hline P55285 & Cadherin-6 & 3489043.13 & 4004248.28 & 0.87 \\
\hline Q9BQT9 & Calsyntenin-3 & 5017718.13 & 8042429.76 & 0.62 \\
\hline Q15782 & Chitinase-3-like protein 2 & 2199432.66 & 1077159.16 & 2.04 \\
\hline P81605 & Dermcidin & 4688516.24 & 17917922.03 & 0.26 \\
\hline P35555; P35556 & Fibrillin-1 & 3553230.87 & 1303085.21 & 2.73 \\
\hline Q99880 & Histone $\mathrm{H} 2 \mathrm{~B}$ & 8827050.37 & 2170205.15 & 4.07 \\
\hline P62805 & Histone H4 & 20150328.18 & 4724728.50 & 4.26 \\
\hline P01857 & $\operatorname{Ig} \gamma-1$ chain $\mathrm{C}$ region & 18124221796.09 & 8578034664.42 & 2.11 \\
\hline P01825 & Ig heavy chain V-II region NEWM & 113679746.37 & 17005522.52 & 6.68 \\
\hline P01766; P01777 & Ig heavy chain V-III region BRO & 210800054.64 & 108040726.11 & 1.95 \\
\hline P01781; P01782 & Ig heavy chain V-III region GAL & 59278269.66 & 29245270.55 & 2.03 \\
\hline P01763 & Ig heavy chain V-III region WEA & 7991860.67 & 1210020.45 & 6.60 \\
\hline P01834 & Ig $\kappa$ chain $\mathrm{C}$ region & 7421686935.61 & 4036338437.24 & 1.84 \\
\hline P01605 & Ig $\kappa$ chain V-I region Lay & 41600571.15 & 10707363.87 & 3.89 \\
\hline P01617; P06309 & $\begin{array}{l}\text { Ig } \kappa \text { chain V-II region TEW; } \\
\text { Ig } \kappa \text { chain V-II region GM607 }\end{array}$ & 55362279.11 & 19775351.47 & 2.80 \\
\hline P01620; P01623 & $\begin{array}{l}\text { Ig } \kappa \text { chain } \mathrm{V}-\mathrm{III} \text { region } \mathrm{SIE} \text {; } \\
\text { Ig } \kappa \text { chain } \mathrm{V}-\mathrm{III} \text { region WOL }\end{array}$ & 659546894.77 & 339679756.20 & 1.94 \\
\hline P01591 & Immunoglobulin $\mathrm{J}$ chain & 25385476.42 & 4918885.36 & 5.16 \\
\hline P48740 & Mannan-binding lectin serine protease 1 & 7385683.45 & 4596167.68 & 1.61 \\
\hline P01033 & Metalloproteinase inhibitor 1 & 53788707.99 & 39003493.11 & 1.38 \\
\hline Q7Z7M0 & $\begin{array}{l}\text { Multiple epidermal growth factor-like } \\
\text { domains protein } 8\end{array}$ & 31947506.55 & 51970874.53 & 0.61 \\
\hline Q9P2E7 & Protocadherin-10 & 632760.49 & 976797.51 & 0.65 \\
\hline P23468 & Receptor-type tyrosine-protein phosphatase $\delta$ & 20936254.05 & 27150962.38 & 0.77 \\
\hline P23470 & Receptor-type tyrosine-protein phosphatase $\gamma$ & 11604652.61 & 16665947.45 & 0.70 \\
\hline Q9BZR6 & Reticulon-4 receptor & 32256800.25 & 53751437.42 & 0.60 \\
\hline Q9ULF5 & Zinc transporter ZIP10 & 2903174.78 & 4387902.38 & 0.66 \\
\hline
\end{tabular}

${ }^{\mathrm{a}} \mathrm{A}$ median LFQ value is shown for the two cohorts studied along with median ratio.

chain $\mathrm{C}$ region, $\mathrm{Ig}$ heavy chain $\mathrm{V}$-III region $\mathrm{BRO}$ and $\mathrm{Ig} \kappa$ chain $\mathrm{C}$ region. These proteins share a common role in initial complement triggering (11).

Complement activation occurs due to a cascade of proteolytic steps performed by serine proteases. Ingram et al performed an immunohistochemical study and identified a set of complement proteins, activation products and regulators in the brain and spinal cord tissue of patients with progressive MS (32). Active, chronic active and chronic inactive MS plaques, as well as non-plaque areas, were examined, and MS plaques were consistently positive for complement proteins (C3, factor B and C1q), activation products (C3b, iC3b, C4d and terminal complement complex), and regulators (factor $\mathrm{H}$, C1-inhibitor and clusterin), suggesting continued local complement synthesis, activation and regulation despite the absence of other evidence of on-going inflammation (32).

Similarly, the data presented by Ekdahl et al showed that MS patients suffering from acute RR MS have more prominent systemic complement activation than MS patients who respond to interferon- $\beta$ treatment. In particular, an increased systemic $\mathrm{C} 3 \mathrm{a} / \mathrm{C} 3$ ratio may serve as a biomarker to distinguish more acute RR MS at an earlier stage of MS pathogenesis (33).

Our prior understanding of the immunology of MS and the knowledge gained from animal studies indicate that complement does not initiate disease but instead propagates on-going disease, with an increased contribution over the course of the disease (34). As a result, some of these proteins were considered risk factors for earlier conversion from CIS to RR MS or secondary progressive (SP) MS during the natural course of the disease.

Chitinase 3-like protein 2 was also identified as a risk factor for MS progression (35). This protein is thought to play a role in the process of inflammation and tissue remodelling.

Diffusion survival evasion protein (DSEP) is encoded in the genomes of humans, primates and rats and has known cytoprotective effects when produced during cell stress. When this molecule is degraded, the N-terminal peptides preserve this function, in contrast to the antimicrobial 


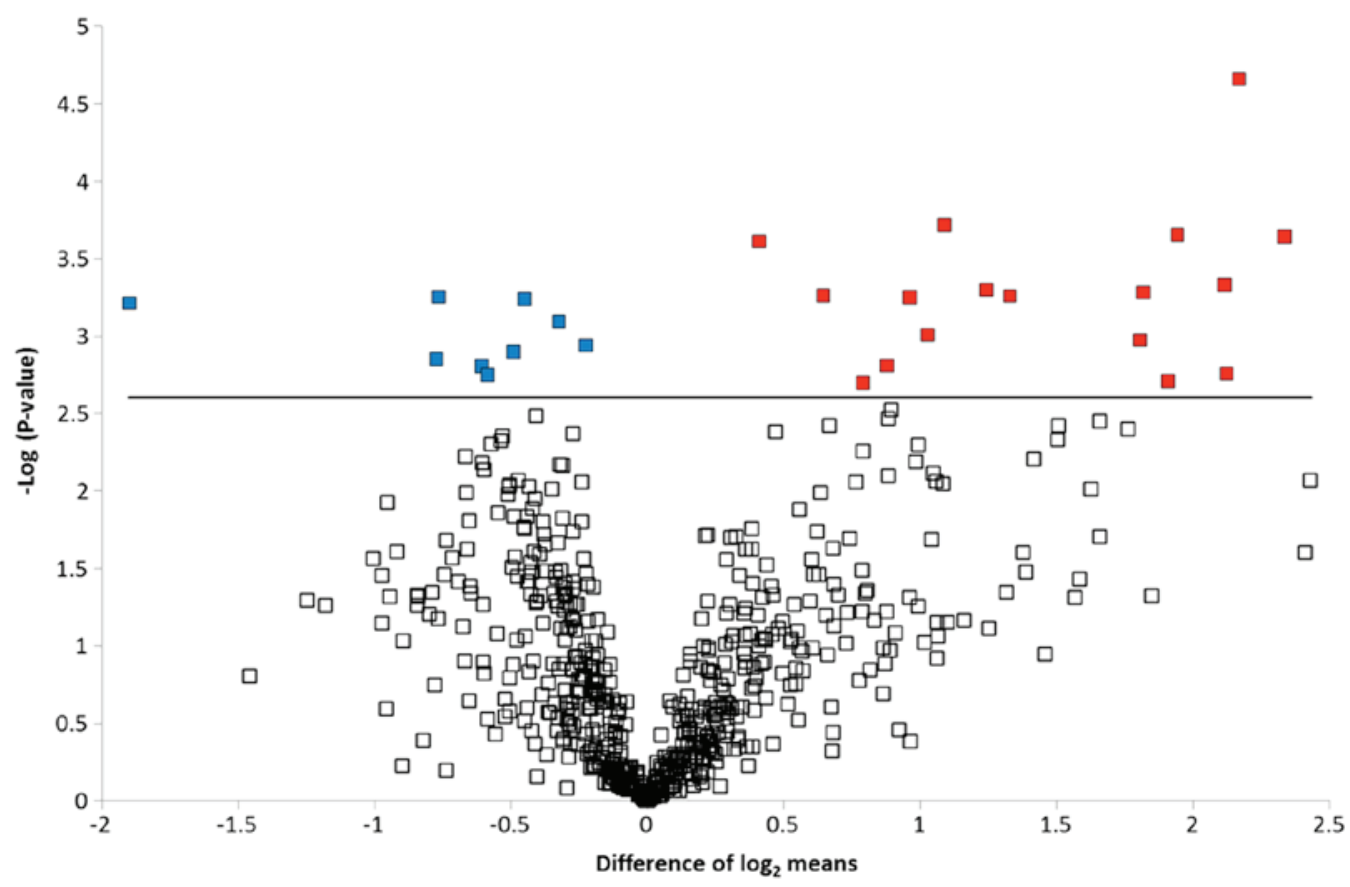

Figure 2. Volcano plot showing significantly dysregulated proteins. The -log (P-value) is plotted against the difference of the means of the two groups (case and control). Points above the non-axial horizontal line are significantly differentially abundant proteins. Seventeen proteins were found to be significantly $(\mathrm{P}<0.002)$ more abundant in the case samples, while nine proteins were significantly less abundant in the case samples.

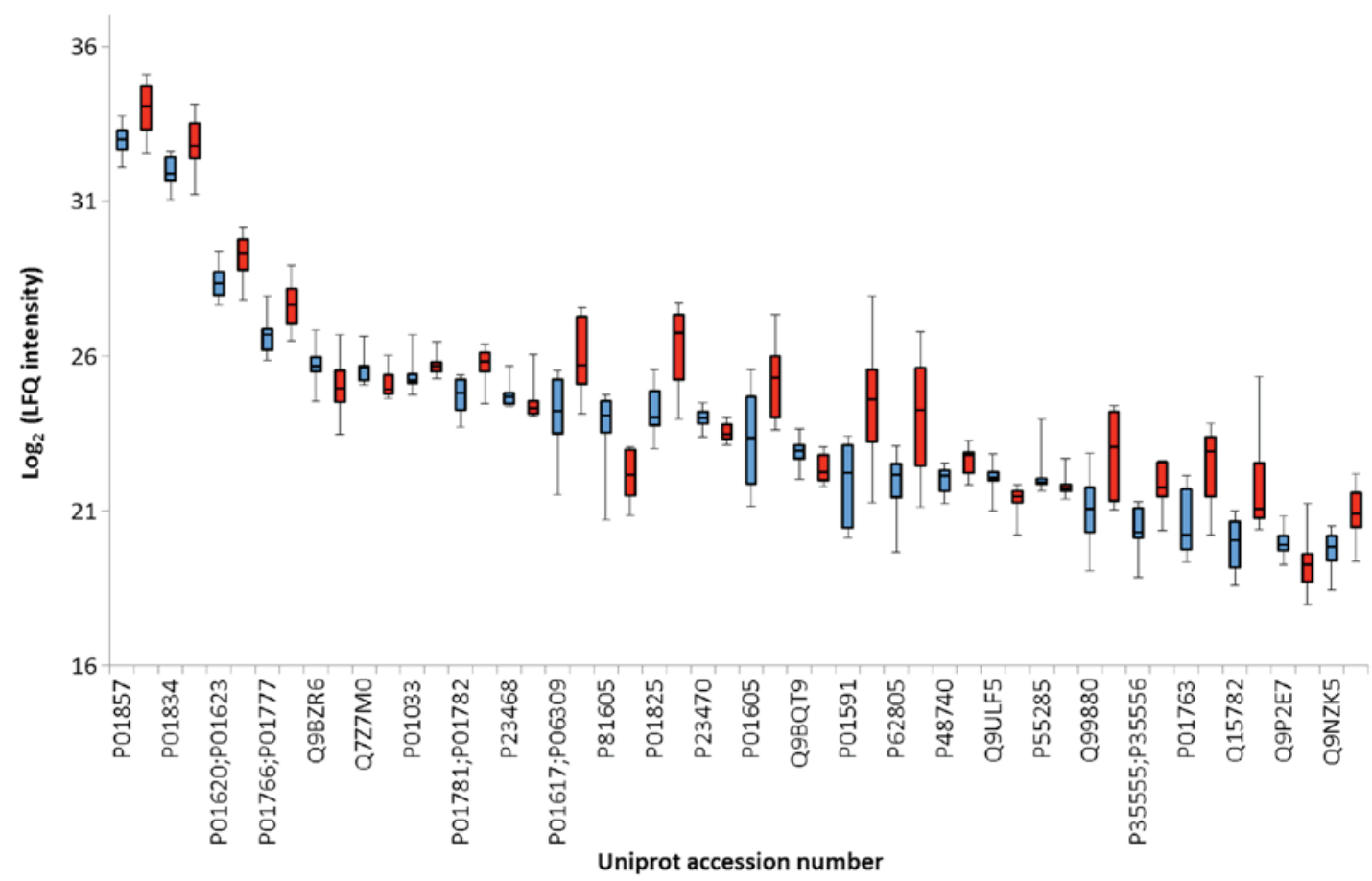

Figure 3. A boxplot graph showing differences in controls (blue bars) vs. case (red bars) for each of the dysregulated proteins. Each boxplot shows protein concentration median, interquartile ranges and the most extreme values.

functions of the C-terminal peptides (Dermcidin). In vitro administration of the $\mathrm{N}$-terminal peptides was shown to promote the formation of monomeric forms of heat shock protein 70 (Hsp70) from oligomeric forms, thereby activating its ATPase activity and resulting in its association with the peptide and Hsp40 to produce an active multimolecular complex, which provides cytoprotection against anoxic and inflammatory insults. The anti-inflammatory effects of these peptides include the inhibition of pro-inflammatory cytokines (TNF- $\alpha$ and IL-6), the inhibition of secretory phospholipase A2, reduced phagocytosis, and the induction of IL-10 secretion (36).

In conclusion, in the present study, we identified three proteins that occurred only in patients with RR MS and these 
proteins may serve as prognostic biomarkers for identifying patients at a high risk of developing RR MS.

\section{Acknowledgements}

The present study was supported by the MH CZ-DRO (UHHK, 00179906).

\section{References}

1. Krejsek J: News in the pathogenesis of multiple sclerosis. What is hidden behind the disability of MS patients. Remedia 2014: S2-S4, 2014 (In Czech).

2. Cree B and Vollmer TL: Clinically isolated syndrome: Evaluation, risk stratification, and treatment decisions. Adv Stud Med 8: 257-265, 2008.

3. Garcea O, Villa A, Cáceres F, Adoni T, Alegría M, Barbosa Thomaz R, Buzo R, Llamas López L and Rivera Kindel M: Early treatment of multiple sclerosis: A Latin American experts meeting. Mult Scler 15 (Suppl 3): S1-S12, 2009.

4. Schumacher GA, Beebe G, Kibler RF, Kurland LT, Kurtzke JF, McDowell F, Nagler B, Sibley WA, Tourtellotte WW and Willmon TL: Problems of experimental trials of therapy in multiple sclerosis: report by the panel on the evaluation of experimental trials of therapy in multiple sclerosis. Ann N Y Acad Sci 122: 552-568, 1965.

5. Poser CM, Paty DW, Scheinberg L, McDonald WI, Davis FA, Ebers GC, Johnson KP, Sibley WA, Silberberg DH and Tourtellotte WW: New diagnostic criteria for multiple sclerosis: Guidelines for research protocols. Ann Neurol 13: 227-231, 1983.

6. McDonald WI, Compston A, Edan G, Goodkin D, Hartung HP, LublinFD,McFarlandHF,Paty DW,Polman CH,ReingoldSC, etal: Recommended diagnostic criteria for multiple sclerosis: guidelines from the International Panel on the diagnosis of multiple sclerosis. Ann Neurol 50: 121-127, 2001.

7. Polman CH, Reingold SC, Edan G, Filippi M, Hartung HP Kappos L,LublinFD,MetzLM,McFarlandHF,O'ConnorPW,etal: Diagnostic criteria for multiple sclerosis: 2005 revisions to the 'McDonald Criteria'. Ann Neurol 58: 840-846, 2005.

8. Polman CH, Reingold SC, Banwell B, Clanet M, Cohen JA, Filippi M, Fujihara K, Havrdova E,Hutchinson M, Kappos L, et al: Diagnostic criteria for multiple sclerosis: 2010 revisions to the McDonald criteria. Ann Neurol 69: 292-302, 2011.

9. Tintoré M: Rationale for early intervention with immunomodulatory treatments. J Neurol 255 (Suppl 1): 37-43, 2008.

10. Miller JR: The importace of early diagnosis of multiple sclerosis, J Manag Care Pharm 10: S4-S11, 2004.

11. Kroksveen AC, Guldbrandsen A, Vedeler C, Myhr KM Opsahl JA and Berven FS: Cerebrospinal fluid proteome comparison between multiple sclerosis patients and controls. Acta Neurol Scand Suppl 195: 90-96, 2012.

12. Kroksveen AC, Opsahl JA, Aye TT, Ulvik RJ and Berven FS: Proteomics of human cerebrospinal fluid: discovery and verification of biomarker candidates in neurodegenerative diseases using quantitative proteomics. J Proteomics 74: 371-388, 2011.

13. Ottervald J, Franzén B, Nilsson K, Andersson LI, Khademi M, Eriksson B, Kjellström S, Marko-Varga G, Végvári A, Harris RA, et al: Multiple sclerosis: identification and clinica evaluation of novel CSF biomarkers. J Proteomics 73: 1117-1132, 2010 .

14. Kroksveen AC, Aasebø E, Vethe H, Van Pesch V, Franciotta D, Teunissen CE, Ulvik RJ, Vedeler C, Myhr KM, Barsnes H, et al: Discovery and initial verification of differentially abundant proteins between multiple sclerosis patients and controls using iTRAQ and SID-SRM. J Proteomics 78: 312-325, 2013.

15. Comabella M, Fernández M, Martin R, Rivera-Vallvé S, Borrás E, Chiva C, Julià E, Rovira A, Cantó E, Alvarez-Cermeño JC, et al: Cerebrospinal fluid chitinase 3-like 1 levels are associated with conversion to multiple sclerosis. Brain 133: 1082-1093, 2010.

16. Stoop MP, Singh V, Dekker LJ, Titulaer MK, Stingl C, Burgers PC, Sillevis Smitt PA, Hintzen RQ and Luider TM: Proteomics comparison of cerebrospinal fluid of relapsing remitting and primary progressive multiple sclerosis. PLoS One 5: e12442, 2010

17. Cox J and Mann M: MaxQuant enables high peptide identification rates, individualized p.p.b.-range mass accuracies and proteome-wide protein quantification. Nat Biotechnol 26: 1367-1372, 2008.
18. Cox J, Neuhauser N, Michalski A, Scheltema RA, Olsen JV and Mann M: Andromeda: a peptide search engine integrated into the MaxQuant environment. J Proteome Res 10: 1794-1805, 2011.

19. Cox J, Hein MY, Luber CA, Paron I, Nagaraj N and Mann M: Accurate proteome-wide label-free quantification by delayed normalization and maximal peptide ratio extraction, termed MaxLFQ. Mol Cell Proteomics 13: 2513-2526, 2014.

20. Gautier L, Cope L, Bolstad BM and Irizarry RA: affy - analysis of Affymetrix GeneChip data at the probe level. Bioinformatics 20: 307-315, 2004.

21. Yang YH, Dudoit S, Luu P, Lin DM, Peng V, Ngai J and Speed TP: Normalization for cDNA microarray data: a robust composite method addressing single and multiple slide systematic variation. Nucleic Acids Res 30: e15, 2002.

22. Christin C, Hoefsloot HC, Smilde AK, Hoekman B, Suits F, Bischoff R and Horvatovich P: A critical assessment of feature selection methods for biomarker discovery in clinical proteomics. Mol Cell Proteomics 12: 263-276, 2013.

23. Clough T, Thaminy S, Ragg S, Aebersold R and Vitek O: Statistical protein quantification and significance analysis in label-free LC-MS experiments with complex designs. BMC Bioinformatics 13 (Suppl 16): S6, 2012.

24. Lipsy RJ, Schapiro RT and Prostko CR: Current and future directions in MS management: key considerations for managed care pharmacists. J Manag Care Pharm 15 (Suppl A): S2-S15, quiz S16-S17, 2009.

25. Mareš J: Early treatment of multiple sclerosis - treatment of clinically isolated syndrome, conditions of early diagnosis and treatment of multiple sclerosis. Remedia 2011: S5-S6 (In Czech)

26. Tintoré M, Rovira A, Río J, Nos C, Grivé E, Téllez N, Pelayo R, Comabella M, Sastre-Garriga J and Montalban X: Baseline MRI predicts future attacks and disability in clinically isolated syndromes. Neurology 67: 968-972, 2006

27. Fisniku LK, Brex PA, Altmann DR, Miszkiel KA, Benton CE Lanyon R, Thompson AJ and Miller DH: Disability and T2 MRI lesions: a 20-year follow-up of patients with relapse onset of multiple sclerosis. Brain 131: 808-817, 2008.

28. Pérez-Miralles F, Sastre-Garriga J, Tintoré M, Arrambide G, Nos C, Perkal H, Río J, Edo MC, Horga A, Castilló J, et al: Clinical impact of early brain atrophy in clinically isolated syndromes. Mult Scler 19: 1878-1886, 2013.

29. Sastre-Garriga J, Tintoré M, Rovira A, Grivé E, Pericot I, Comabella M, Thompson AJ and Montalban X: Conversion to multiple sclerosis after a clinically isolated syndrome of the brainstem: cranial magnetic resonance imaging, cerebrospinal fluid and neurophysiological findings. Mult Scler 9: 39-43, 2003.

30. Neuteboom RF, Boon M, Catsman Berrevoets CE, Vles JS, Gooskens RH, Stroink H, Vermeulen RJ, Rotteveel JJ, Ketelslegers IA, Peeters E, et al: Prognostic factors after a first attack of inflammatory CNS demyelination in children. Neurology 71: 967-973, 2008

31. Tintoré M, Rovira A, Río J, Tur C, Pelayo R, Nos C, Téllez N, Perkal H, Comabella M, Sastre-Garriga J, et al: Do oligoclonal bands add information to MRI in first attacks of multiple sclerosis? Neurology 70: 1079-1083, 2008.

32. Ingram G, Loveless S, Howell OW, Hakobyan S, Dancey B, Harris CL, Robertson NP, Neal JW and Morgan BP: Complement activation in multiple sclerosis plaques: an immunohistochemical analysis. Acta Neuropathol Commun 2: 53, 2014.

33. Ekdahl NK, Blomberg C, Henningsson JA, Dahle C, Håkanssone I, Sandholm K and Ernerudh J: Systemic and intrathecal complement activation in multiple sclerosis and Guillan-Barré syndrome. Mol Immunol 46: 2848, 2009.

34. Ingram G, Hakobyan S, Robertson NP and Morgan BP: Complement in multiple sclerosis: its role in disease and potential as a biomarker. Clin Exp Immunol 155: 128-139, 2009.

35. Hinsinger G, Galéotti N, Nabholz N, Urbach S, Rigau V, DematteiC,Lehmann S, Camu W, Labauge P, Castelnovo G, etal: Chitinase 3-like proteins as diagnostic and prognostic biomarkers of multiple sclerosis. Mult Scler 21: 1251-1261, 2015.

36. Greenstein $\mathrm{J}$ and Cunningham T: Neuroprotective, anti-inflammatory and immune Tolerizing properties of peptides derived from diffusion survival Evasion protein (DSEP)/Dermcidin. Neurology 82: P1.175, 2014. 